Special issue of the 2nd International Conference on Computational and Experimental Science and Engineering (ICCESEN 2015)

\title{
Determination of Natural Radioactivity and Associated Radiological Hazard in Excavation Field in Turkey (Oluz Höyük)
}

\begin{abstract}
B. ÇETIN ${ }^{a, *}$, F. ÖNER ${ }^{b}$ AND İ. AKKURT ${ }^{c}$
${ }^{a}$ Amasya University,Department of Physics, Faculty of Arts and Sciences, Amasya, Turkey

${ }^{b}$ Amasya University, Department of Science Education, Faculty of Education, Amasya, Turkey

${ }^{c}$ Süleyman Demirel University, Department of Physics, Faculty of Arts and Sciences, Isparta, Turkey

The level of natural radioactivity may be varied with the increase in dependence of the depth into the earth. In present study, soil samples from different depths were collected in Oluz Höyük excavation area. The radionuclide concentrations in soil samples were determined by gamma-ray spectrometer which contains 3 " $\times 3$ " $\mathrm{NaI}(\mathrm{Tl})$ detector connected to multichannel analyser. The photopeaks at 1460,1764 , and $2615 \mathrm{keV}$ due to ${ }^{40} \mathrm{~K},{ }^{226} \mathrm{Ra}$ and ${ }^{232} \mathrm{Th}$, respectively, have been used. The obtained activity concentrations of ${ }^{40} \mathrm{~K},{ }^{226} \mathrm{Ra}$ and ${ }^{232} \mathrm{Th}$ ranged from 656.03 to $1791.85 \mathrm{~Bq} / \mathrm{kg}, 62.39$ to $180.93 \mathrm{~Bq} / \mathrm{kg}$ and 48.31 to $125.43 \mathrm{~Bq} / \mathrm{kg}$, respectively. To assess the radiological hazard of the natural radionuclides content in the soil samples of these area, the radium equivalent activities (the minimum value was $181.99 \mathrm{~Bq} / \mathrm{kg}$ and the maximum value was $497.97 \mathrm{~Bq} / \mathrm{kg}$ ), the absorbed dose rate (the minimum value was $86.83 \mathrm{nGy} / \mathrm{h}$ and the maximum value was $237.22 \mathrm{nGy} / \mathrm{h}$ ), annual effective dose rate (the minimum value was $0.11 \mathrm{mSv} / \mathrm{y}$ and the maximum value was $0.29 \mathrm{mSv} / \mathrm{y}$ ) and external hazard index (the minimum value was 0.49 and the maximum value was 1.35 ) were calculated using measured activities.
\end{abstract}

DOI: 10.12693/APhysPolA.130.475

PACS/topics: 29.40.-n, 29.85.Fj

\section{Introduction}

All living organisms are continually exposed to ionizing radiation coming from natural and artificial radionuclides. Natural radionuclides are found in air, water and soil, which come from terrestrial and cosmic radiation. The major contribution to the terrestrial radiation are primordial radionuclides, mainly ${ }^{238} \mathrm{U}$ and ${ }^{232} \mathrm{Th}$ series and ${ }^{40} \mathrm{~K}$. In the ${ }^{238} \mathrm{U}$ series, the decay chain segment starting from radium $\left({ }^{226} \mathrm{Ra}\right)$ is radiologically most important and therefore often refers to ${ }^{226} \mathrm{Ra}$ instead of ${ }^{238} \mathrm{U}[1]$

Natural radioactivity and the associated external exposure due to gamma radiation depend primarily on the geological and geographical conditions, and appear at different levels in each region in the world [2].

Oluz Höyük, in the Amasya Province, situated in the land zone of the central Black Sea region, resides at the $27 \mathrm{th} \mathrm{km}$ of the Corum main road, in the territory of the Gokhoyuk Agriculture Operation Management. Oluz Höyük, which has dimensions of $280 \times 260 \mathrm{~m}^{2}$, is $15 \mathrm{~m}$ higher than the plate level and has a field of $45,000 \mathrm{~m}^{2}$ and one of the biggest hoyuks of the region [3].

In the presented work, the concentration activities of natural radioactivity were measured in Amasya-Oluz Höyük (Fig. 1) and the radium equivalent activities, the absorbed dose rate, annual effective dose rate, and

\footnotetext{
*corresponding author; e-mail: betulcetin3205@gmail.com
}

external hazard index were calculated using measured activities.

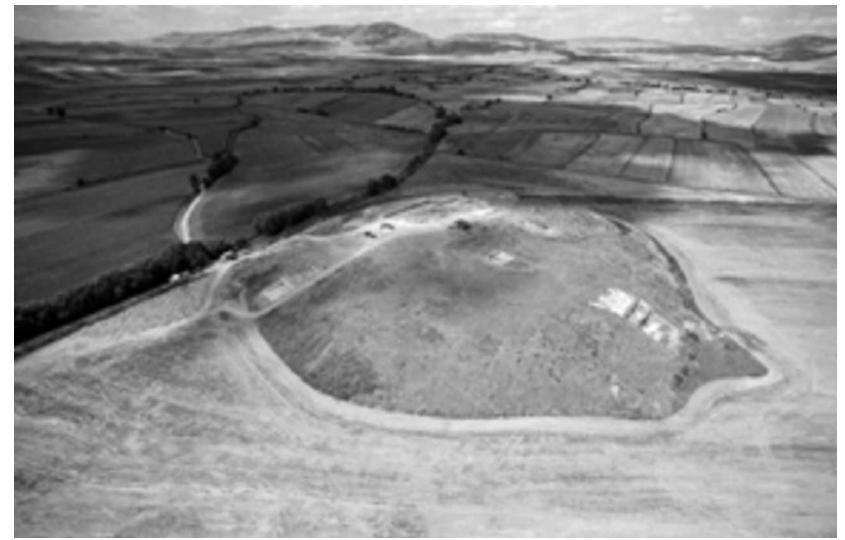

Fig. 1. Oluz Höyük excavation area, Amasya, Turkey.

The historical artefacts extracted from the Oluz Höyük excavations in Amasya which are continued, make a significant contribution to cultural heritage. According to Oluz Höyük excavation [3], the 0 layer of the Oluz Höyük could be dated to middle age; the 1st architectural layer to hellenistic period (the end of 2 nd century $\mathrm{BC}$ and the beginning of the 1st century $\mathrm{BC}$ ); the 2nd architectural layer to the late phase of the late iron age (4th and 3rd centuries BC). The 3rd and 4th architectural layers could be dated to the early phase of the late iron age (6th and 5th centuries $\mathrm{BC}$ ), 5th architectural layer to the middle iron age (7th century BC) and 6th architectural layer to 
possibly either early iron age or late bronze age in other words, to the age of Hittite empire period [4].

Therefore, it would be interesting to measure natural radioactivity and to assess the exchange of ${ }^{40} \mathrm{~K}$, ${ }^{226} \mathrm{Ra}$, and ${ }^{232} \mathrm{Th}$ activity concentrations depending on the depth of the soil samples using gamma spectrometer in a such interesting field.

\section{Experimental procedures}

\subsection{Sample collection and preparation}

Soil samples were collected from different layers of soil down to $10-15,50-60,70-80,110-120,130-140,160$ 170, 180-190 cm depth in the Oluz Höyük excavation area. The samples were crushed, sieved and dried in an oven at $100{ }^{\circ} \mathrm{C}$ for about $20 \mathrm{~h}$ to ensure that moisture is completely removed. The weight was determined for each sample. Then they were put in polyethylene containers and sealed. The samples were submitted to gamma readings after waiting for ${ }^{222} \mathrm{Rn}$ to reach secular equilibrium with ${ }^{226} \mathrm{Ra}$ (more than one month) [5].

\subsection{Sample measurement}

The natural radioactivity concentration of soil samples were measured using the gamma spectrometer, containing a 3" $\times 3$ " $\mathrm{NaI}(\mathrm{Tl})$ detector coupled to a digital spectrum analyzer (DSPEC LF) which was connected to the 16k channels multichannel analyser (MCA) provided by Ortec hardware controlled by MAESTRO-32 software.

The counting time for each sample and background was $72,000 \mathrm{~s}$; for getting net counts of the samples we take the difference between background and sample measurement for the same counting time.

The ${ }^{226} \mathrm{Ra}$ and ${ }^{232} \mathrm{Th}$ activity concentrations were determined by the photopeaks of their daughters, respectively, ${ }^{214} \mathrm{Bi}(1764 \mathrm{keV})$ and ${ }^{208} \mathrm{Tl}(2615 \mathrm{keV})$. The ${ }^{40} \mathrm{~K}$ activity concentration was determined directly by $1460 \mathrm{keV}$ photopeak.

\section{Results and discussion}

\subsection{Radioactivity concentration}

The activity concentrations of ${ }^{40} \mathrm{~K},{ }^{226} \mathrm{Ra}$ and ${ }^{232} \mathrm{Th}$ in the measured samples dry soil in $\mathrm{Bq} / \mathrm{kg}$ were computed using the following equation relation:

$$
A=\frac{C}{\varepsilon \gamma m},
$$

where $A$ is the counting rate of gamma rays in $\mathrm{Bq} / \mathrm{kg}, C$ [cps] is the net count rate under the most prominent photopeaks calculated by subtracting the respective count rate from the background spectrum obtained for the same counting time. The net count rate in the measurement is calculated from the background subtracted area of prominent gamma ray peaks. $\varepsilon$ is the detector efficiency of the specific gamma ray, $\gamma$ - the absolute transition probability of gamma decay and $m$ - the mass of the sample $(\mathrm{kg})[5]$. The worldwide average concentrations of the radionuclides are $32 \mathrm{~Bq} / \mathrm{kg}$ for ${ }^{226} \mathrm{Ra}$ and $45 \mathrm{~Bq} / \mathrm{kg}$ for ${ }^{232} \mathrm{Th}$ and $412 \mathrm{~Bq} / \mathrm{kg}$ for ${ }^{40} \mathrm{~K}[6]$.

The activity concentrations of ${ }^{40} \mathrm{~K},{ }^{226} \mathrm{Ra}$, and ${ }^{232} \mathrm{Th}$ ranged from 656.03 to $1791.85 \mathrm{~Bq} / \mathrm{kg}, 62.39$ to $180.93 \mathrm{~Bq} / \mathrm{kg}$ and 48.31 to $125.43 \mathrm{~Bq} / \mathrm{kg}$, respectively are shown in Fig. 2.

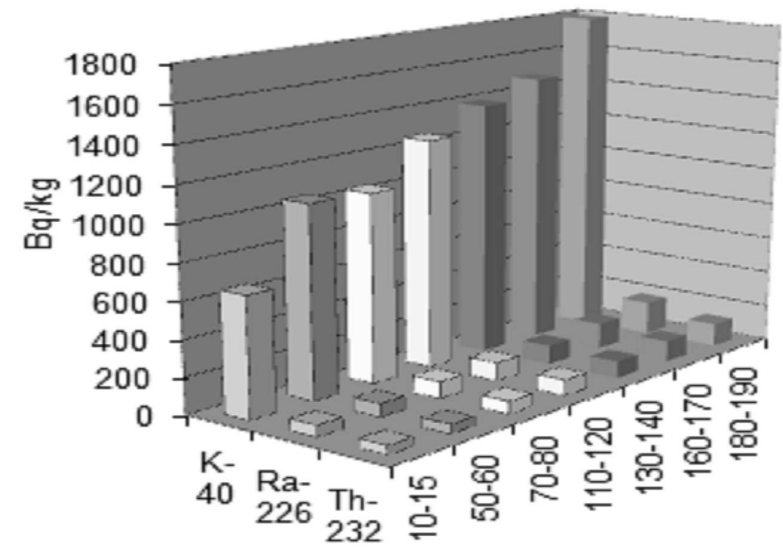

Fig. 2. 3D spectrum for ${ }^{40} \mathrm{~K},{ }^{226} \mathrm{Ra}$, and ${ }^{232}$ Th activity concentration in soil samples.

\subsection{Calculation of the radiological effects}

\subsubsection{Radium equivalent activity $\left(R a_{\mathrm{eq}}\right)$}

To assess the radiological risk of the materials, it is useful to calculate an index called the radium equivalent activity, $\mathrm{Ra}_{\mathrm{eq}}(\mathrm{Bq} / \mathrm{kg})$, which is a common index used to compare the activity concentrations of samples containing ${ }^{40} \mathrm{~K},{ }^{226} \mathrm{Ra}$, and ${ }^{232} \mathrm{Th}$. It is a weighted sum of activities on the base assumption that $370 \mathrm{~Bq} / \mathrm{kg}$ of ${ }^{226} \mathrm{Ra}, 259 \mathrm{~Bq} / \mathrm{kg}$ of ${ }^{232} \mathrm{Th}$ or $4810 \mathrm{~Bq} / \mathrm{kg}$ of ${ }^{40} \mathrm{~K}$ produce the same gamma-ray dose rate $[7,8]$. $\mathrm{Ra}_{\mathrm{eq}}$ is calculated through the following equation as described by UNSCEAR, 1982 [6]:

$$
\mathrm{Ra}_{\mathrm{eq}}=A_{\mathrm{Ra}}+1.43 A_{\mathrm{Th}}+0.077 A_{\mathrm{K}},
$$

where $A_{\mathrm{Ra}}, A_{\mathrm{Th}}$ and $A_{\mathrm{K}}$ are the activity concentrations of ${ }^{226} \mathrm{Ra},{ }^{232} \mathrm{Th}$ and ${ }^{40} \mathrm{~K}$, respectively, in $\mathrm{Bq} / \mathrm{kg}$. The results have ranged from 181.99 to $497.97 \mathrm{~Bq} / \mathrm{kg}$ as shown in Fig. 3.

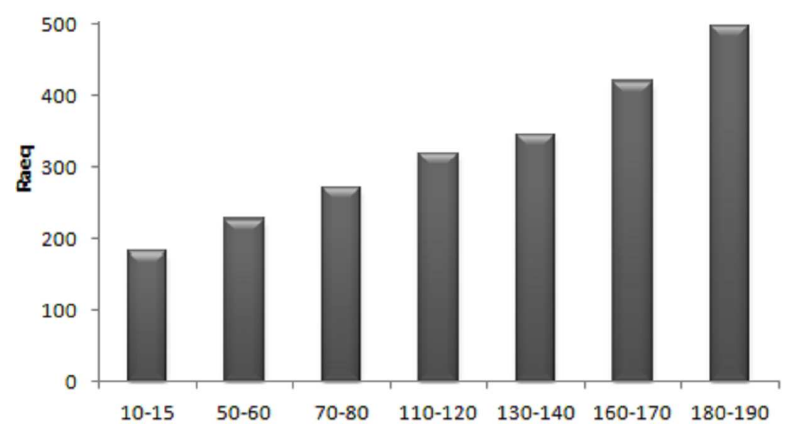

Fig. 3. Radium equivalent activity for soil samples. 


\subsubsection{Absorbed dose rate (D)}

If naturally occurring radioactive nuclides are uniformly distributed, absorbed dose rates (nGy/h) according to UNSCEAR report can be calculated for the sand and sandstone by the following formula [9]:

$$
D=0.042 C_{\mathrm{K}}+0.429 C_{\mathrm{Ra}}+0.666 C_{\mathrm{Th}}
$$

It can be seen that the absorbed dose rate ranged from 86.83 to $237.22 \mathrm{nGy} / \mathrm{h}$ as shown in Fig. 4. This is within the world range 18-93 $\mathrm{nGy} / \mathrm{h}[10]$ and recommended average value $55 \mathrm{nGy} / \mathrm{h}[9]$. The absorbed dose values are higher than recommended average value but this is within the world range value.

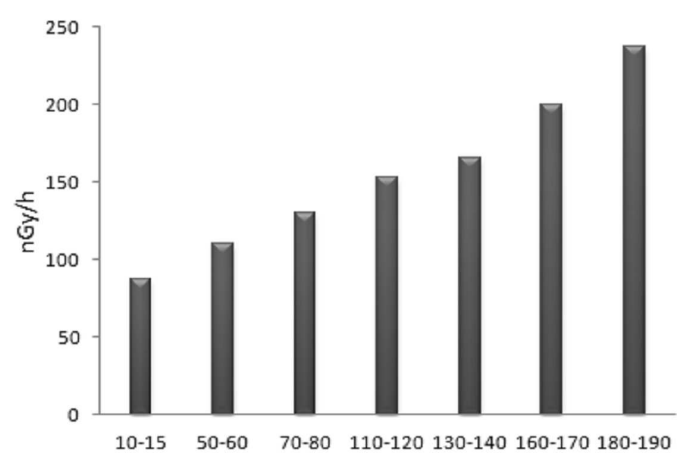

Fig. 4. Absorbed dose rate for soil samples.

\subsubsection{Annual effective dose rate (AEDR)}

The outdoor annual effective dose can be estimated using the conversion coefficient from the absorbed dose to the effective dose $(0.7 \mathrm{~Sv} / \mathrm{Gy})$ and the people implying that $20 \%$ of time is spent outdoors, proposed by UNSCEAR, 2000 [10].

International Commission on Radiological Protection (ICRP) has recommended the annual effective dose equivalent limit of $1 \mathrm{mSv} / \mathrm{y}$ for the individual members of the public and $20 \mathrm{mSv} / \mathrm{y}$ for the radiation workers [11].

The obtained AEDR values have ranged from 0.11 to $0.29 \mathrm{mSv} / \mathrm{y}$ in Fig. 5 . The results were compared with the UNSCEAR limit where the average AEDR from the terrestrial radionuclide is $1 \mathrm{mSv} / \mathrm{y}$ [10]. The calculated AEDR values are lower than the recommended UNSCEAR limit value.

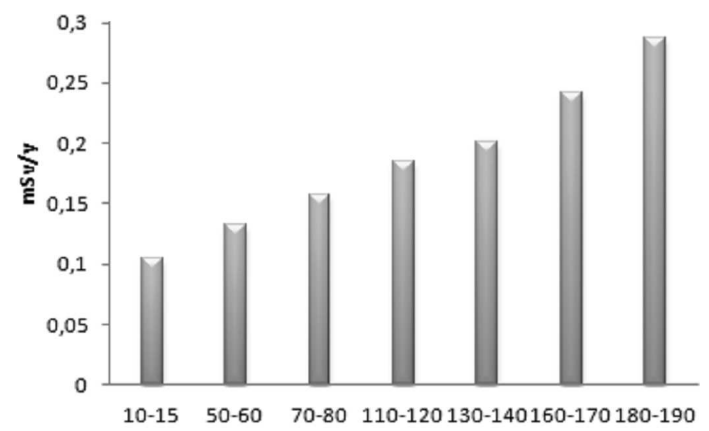

Fig. 5. Annual effective dose rate for soil samples.

\subsubsection{External radiation hazard index $\left(H_{\mathrm{ex}}\right)$}

External radiation hazard index due to the emitted gamma rays of the samples is calculated from the equation [7]:

$$
H_{\mathrm{ex}}=C_{\mathrm{Ra}} / 370+C_{\mathrm{Th}} / 259+C_{\mathrm{K}} / 4810 \leq 1 .
$$

The value of $H_{e x}$ must be less than unity. The results range from 0.49 to 1.35 are given in Fig. 6. It is clear that all measured results are much lower than the upper limit of the unity except two depths.

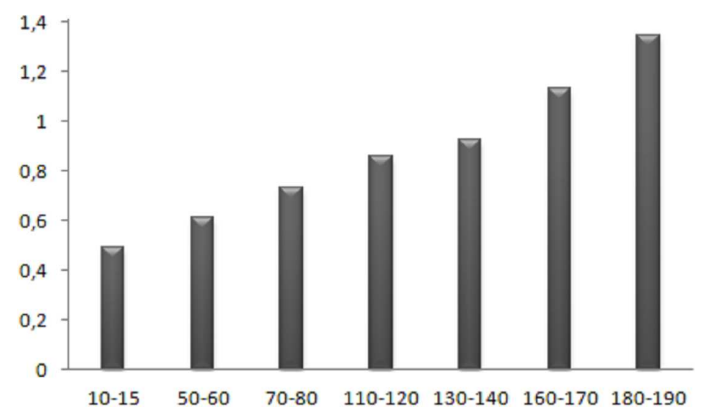

Fig. 6. Hazard index for soil samples and comparison with the limit value of the unity.

\section{Conclusions}

From these results we can infer that the general distribution of activity concentrations are within tolerable levels considering that the soil samples will not be used as building material. Furthermore, the calculated radiological effect is lower than the recommended limit value except for two samples. The radium equivalent activities obtained for the samples in this study were all below the recommended limit values $(370 \mathrm{~Bq} / \mathrm{kg})$. The value of external hazard indices are less than unity.

\section{Acknowledgments}

Scientific Research Projects Unit of Amasya University (FMB-BAP-020) supported this study. The authors wish to thank Professor Ş. Dönmez, the staff of the Oluz Höyük excavation team and Amasya Museum Director.

\section{References}

[1] R. Ravisankar, K. Vanasundari, A. Chandrasekaran, M. Suganya, P. Eswaran, P. Vijayagopal, V. Meenakshisundaram, Arch. Phys. Res. 2, 95 (2011).

[2] A.I. Abd El-Mageed, A.H. El-Kamel, A. Abbady, S. Harb, A.M.M. Youssef, I.I. Saleh, Radiat. Phys. Chem. 80, 710 (2011).

[3] F.A. Yüksel, N. Hoşkan, Ş. Dönmez, in: Proc. Symp. on the Application of Geophysics to Engineering and Environmental Problems (SAGEEP), Ed. J.J. LoCoco, Keystone (CO) 2010, p. 968.

[4] Ş. Dönmez, Project of Oluz Höyük Excavation, 2013. 
[5] B. Mavi, I. Akkurt, Radiat. Phys. Chem. 79, 933 (2010).

[6] United Nations, Ionizing Radiation: Sources and Biological Effects, UNSCEAR, New York 1982, Report to the General Assembly, with annexes.

[7] J. Beretka, P.J. Mathew, Health Phys. 48, 87 (1985).

[8] E.M. Krisiuk, S.I. Tarasov, V.P. Shamov, N.I. Shlak, E.P. Lisachenko, L.G. Gomslsky, A Study of Radioactivity in Building Materials, Research Institute of Radiation Hygiene, Leningrad 1971.
[9] United Nations, Sources, Effects and Risks of Ionizing Radiation, UNSCEAR, New York 1988, Report to the General Assembly, with annexes.

[10] United Nations, Exposure from Natural Sources, Annex B, UNSCEAR, New York 2000, Report to the General Assembly.

[11] International Commission on Radiological Protection, Protection Against Radon-222 at Home and at Work, ICRP Publication 65, Annals of the ICRP 23, ICRP Pergamon Press, Oxford 1993. 